for the year by 17 lakhs of bales. The yield of the crop in 1939-40 was more than 109 lakhs of bales and the jute crop of 1940-41 is expected to give a record yield of 125 lakhs of bales. The consumption of raw jute this season is likely to be abnormally low, and a considerable quantity of jute is expected to be left over from the crop of 1941. The bulletin embodies the results of investigations carried out by the Economic Research Sub-Section of the Committee.

\section{Cements for Glass Inserts in Electrical Apparatus}

THe fixing of glass or porcelain insulators to metal parts by means of cement in the construction of switch gear and other apparatus has been a practice employed since the early days of electrical apparatus. At one time a mixture of sulphur and ground glass was extensively used for porcelain, the well-known litharge and glycerine cement being employed for the finer classes of work. This latter material is still in extensive use, but much work is also done with cements of the calcium sulphate type. As certain new products of this latter class have been introduced, an investigation has been carried out by the British Electrical and Allied Industries Research Association in order to elicit information bearing on the performance of these materials in practice (Technical Report, Ref. G./T. 131, "Recent Experience with Calcium Sulphate and other Types of Cement for Glass Inserts in Flame-proof Enclosures". By A. P. Paton). A table is given in the report summarizing the information collected on the quantities of cement mixed at a time and used for each article, and the time necessary before the articles could be released from the jigs. The latter varied from a maximum of 48 hours to a minimum of a quarter of an hour. This latter figure was exceptional and referred to meter glasses and windows fixed with Hawkins iron cement. A minimum period of $\frac{1}{3}$ hour was given for flame-proof lighting fittings and cover glasses of housings fixed with C. Fine Keene's cement. The figures, however, varied somewhat and were not elosely connected with the type of cement. In one case it was stated that $2 \frac{1}{2} \mathrm{lb}$. of gum arabic to a gallon of water was used in making up C. Fine Keene's cement. No difference in strength was found, and the cement adhered more firmly to glass or metal.

In certain conditions, C. Fine Keene's cement may give rise to electrolytic action if used with Bakelite. This cement is essentially an anhydrous calcium sulphate, which is slightly acid, due to the addition of a small percentage of alum. The presence of this potassium salt is considered undesirable when the cement is in contact with insulation of the synthetic resin impregnated type. Alternatives which have now been developed are termed Kaffir Plasters. They consist of calcium sulphate hemi-hydrate and are manufactured by Messrs. Cafferata. The product hydrates almost fully within about two hours, so that 'dry out' is almost impossible. The report states that it is a little unfortunate that the word plaster conveys to the general public the idea of a product which is inferior in strength and performance to a 'cement'. Actually, it is technically accepted in the gypsum trade that a cement is a high-temperature dead-burnt product, and that, without exception, all hemi-hydrates are designated plasters. The specially prepared hemi-hydrates known as Kaffir Plasters, while chemically similar to plaster-of-Paris, are different in their mechanical and physical properties, and give strength figures many times higher than those of plaster-of-Paris. They harden rapidly, and jigs may be fixed in 2-3 hours.

\section{Health of the Sudan}

IN his recently issued report for 1939 Dr. E. D. Pridie, director of the Sudan medical service, maintains that in spite of the occurrence of epidemic diseases, especially cerebrospinal fever, relapsing fever, smallpox and measles, the health of the Sudan in that year was very satisfactory. The epidemic of cerebrospinal fever which broke out in Equatoria and was not suppressed by the end of the year, comprised 2,714 cases with 647 deaths-a fatalityrate of 25 per cent against an expected rate of 60 per cent. The mortality at the onset of the epidemic was 80 per cent, but treatment with drugs of the sulphamide class reduced it to about 10 per cent. There were 1,000 cases of relapsing fever with 92 deaths, and 502 cases of smallpox which originated in French Equatorial Africa. On the other hand, the incidence of typhoid fever and bacillary dysentery was low. Although the range of most of them was limited, practically every endemic tropical infection was present in some part of the Sudan.

\section{Earthquake in Alaska}

The United States Coast and Geodetic Survey, in co-operation with Science Service and the Jesuit Seismological Association, has determined the provisional epicentre of the earthquake of July 30, 1941, which took place at $1 \mathrm{~h} .51 .5 \mathrm{~m}$. U.T. This was at latitude $60.9^{\circ} \mathrm{N}$., $149 \cdot 2^{\circ} \mathrm{W}$. which is very near the railway between Seward and Anchorage, Alaska, and about midway between these two places. It is not known whether or not there was any damage due to the earthquake. Alaska and the Aleutian Islands form part of the circum-Pacific ring of instability, around which earthquakes and tremors are fairly frequent. Recently earthquakes have been very frequent among the Aleutian Islands, and what was probably the most notable earthquake of recent years on the mainland occurred on April 26, 1933, to the north-west of the Kenai Peninsular. (Nature, May 27, 1933, p. 757.)

\section{University of London}

DR. H. L. EAson retired from the office of principal on September 30 and Mr. Harold Claughton entered upon his duties as acting principal on October 1.

The title of reader in geography in the University has been conferred on Dr. R. E. Dickinson, in respect of the post held by him at University College.

The degree of D.Sc. has been conferred on the 